Jpn. J. Human Genet. 27, 95-101, 1982

\title{
ABNORMAL PSEUDOCHOLINESTERASE
}

\author{
Iwao IUCHI \\ Department of Biochemistry, Kawasaki Medical School, \\ Matsushima, Kurashiki 701-01, Japan
}

Pseudocholinesterase [acylcholine acyl hydrolase, EC 3.1.1.8, PsChE] also called serum cholinesterase ( $\mathrm{SChE}$ ) is a non-specific esterase which catalyses the hydrolysis of a variety of cholinesters and other esters, particularly those characterized by benzoylcholine as specific substrate and butyrylcholine as substrate preference (Silver, 1974).

The variation of this enzyme activity in ordinary diseases is evaluated properly in clinical pathology and is measured widely by many hospital laboratories in Japan. However, apart from the clinical significance, the PsChE activity may be decreased by the presence of qualitatively aberrant enzymes. The carrier with a PsChE anomaly has no harmful disabilities in daily life, but he has a marked hypersensitivity to choline ester drugs, especially such muscle relaxants as succinyl dicholine (SCC) which is widely and frequently used for short acting muscle relaxation in the induction of anesthesia.

When this drug is injected intravenously into individuals with this anomaly, a dangerous prolonged apnea ( $30 \mathrm{~min}$ to several hours) and asphyxia occur as the result of muscle paralysis, particularly of the respiratory muscles (Pantzuck, 1975). This is now known to be caused by the inability of aberrant PsChE to rapidly hydrolyse SCC.

According to a report of the Danish Cholinesterase Research Unit, a number of 255 patients have been listed as the hypersensitives following an episode of prolonged apnea after administration of SCC during the past four years (Viby-Mogensen and Hanel, 1978). It also reports that approximately $70 \%$ of such patients had an inherited abnormal PsChE with genotypes expressed as $\mathrm{E}_{1} \mathrm{a}_{1}^{\mathrm{a}}, \mathrm{E}_{1} \mathrm{E}_{1}^{\mathrm{s}}, \mathrm{E}_{1} \mathrm{E}_{1}^{\mathrm{u}}$ (see Genetics of PsChE in the text) and the remainder had an aquired deficiency of PsChE due to other non-genetic disorders.

This paper aims to describe the present status of PsChE research in Japan according to current concepts, and to describe our case reports and population survey to determine the frequency of this anomaly in Japan.

\section{Methods of PsChE activity determination and its phenotyping}

An enzymatic hydrolysis of substrate generally takes place in three steps: 1) a complex formation by collision between an enzyme and a substrate, 2) hydrolysis. 
of substrate and finally 3) release of free enzyme. Abnormal PsChE has reduced activity and is less inhibited by inhibitors because the abnormal PsChE has about 100 -fold lower affinity for substrate or inhibitors than the usual enzyme (Kalow, 1959). Therefore, PsChE variants are subtyped by such characteristics as reduced activity and percentage inhibition, called the inhibition number-dibucaine number (DN), fluoride number (FN), chloride number (CN), and others (see below).

A new colorimetric method which has proved to be accurate and useful for subtyping and mass-screening of serum was established by us after careful examination of the methods of Kalow and Lindsay (Kalow and Lindsay, 1955) and Harris and Whittaker (Harris and Whittaker, 1961) 13 years ago (Iuchi, 1969a). This method uses butyrylcholine as substrate and DTNB for coloration of thiocholine, a hydrolysis product of the substrate.

Many competitive and denaturing agents have been introduced as suitable inhibitors for PsChE phenotyping (Whittaker, 1980), such as dibucaine (D), sodium fluoride $(\mathrm{F})$, sodium chloride $(\mathrm{Cl})$, butanol (Alc), pancronium (P), scoline (= suxamethonium) (S), urea (U), sodium bromide (Br), Rosche's agent of Ro2-068, and propranolol (Pr). Of the inhibitors aforelisted, the first two substances (D, F) are the main subtyping agents based on the structural aberrancy of the PsChE molecule, since they interact with the substrate at the anionic and ester sites of the enzyme molecule, respectively. The other compounds might be considered as auxilliarly agents for identification of $\mathrm{D}$ and $\mathrm{F}$ anomalies.

It was felt that the measurement of various inhibition numbers and their inhibition curves as well as family study were essential for phenotyping each PsChE anomaly.

\section{Genetics of PSChE and case reports}

The $E_{1}$ gene locus which is responsible for the production of PSChE has been assigned to chromosome 1 and is sandwiched between the gene for transferrin and phosphogluconate dehydrogenase (Chautard-Freire-Maia, 1977). Four allelic genes functioning at the same locus $\mathrm{E}_{1}$ have been recognized: the usual gene $\mathrm{E}_{1}$, the atypical or dibucaine resistant gene $E_{1}{ }^{2}$, the fluoride resistant gene $E_{1}{ }^{f}$ and the anenzymic also called silent gene $\mathrm{E}_{1}^{\mathrm{s}}$. These gene give rise to ten phenotypes. The homozygotes and double heterozygote in the various combinations involving $\mathrm{E}_{1}{ }^{a}, \mathrm{E}_{1}^{\mathrm{f}}$, and $\mathrm{E}_{1} \mathrm{~s}$ (6 in all) invariably exhibit moderate to severe $\mathrm{SCC}$ hypersensitivity. Other rare genes designated as $E_{1}^{j}, E_{1}^{k}, C_{1}{ }_{1}^{c l}, E_{1}^{a l c}$ have also been reported in the heterozygous condition (Whittaker, 1980).

The first instance of $\mathrm{PSChE}_{\mathrm{S}} \mathrm{anomaly}$ in Japan was discovered by us in 1967 in a $62 \mathrm{yr}$-old male patient with hypertension and encephalomalacia (Shibata et al., 1967). All his biochemical hepatic function tests except for PsChE were within normal range and he had no neoplasms or inflammatory lesions. His $\mathrm{PsChE}$ activity were almost zero around, being $2 \%$ of normal throughout the observation periods over one and a half years. Family study indicated a cluster of consanguineous 

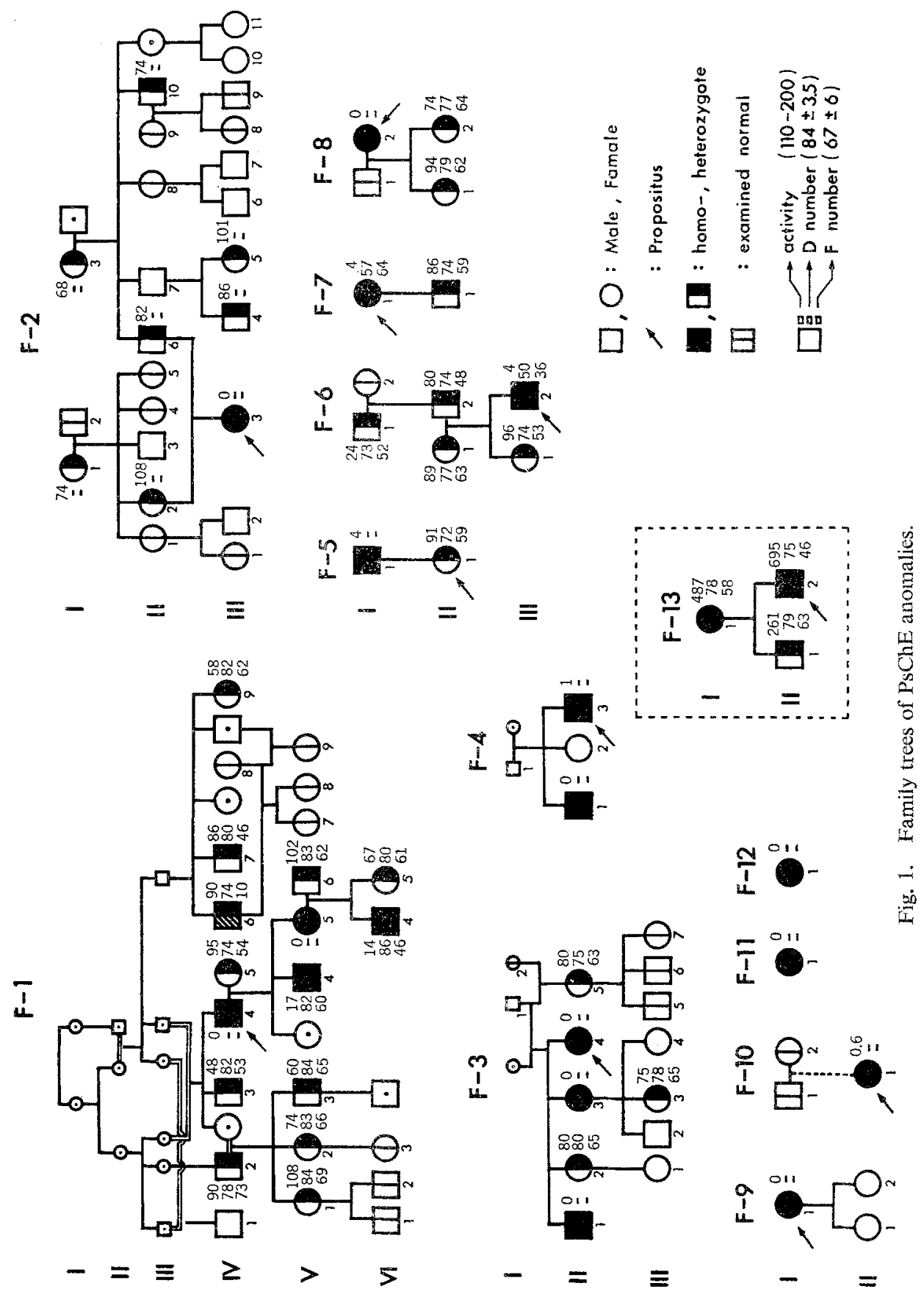
marriages as shown in Fig. 1-1. The individuals shown as IV-5 and V-6 were presumed to have the same common ancestor of unknown generations with proband's family since they originated at the same village. Three homozygotes with $\mathrm{E}_{1} \mathrm{~s}_{1} \mathrm{~s}$, one double heterozygotes with $\mathrm{E}_{1}{ }^{\mathrm{s}} \mathrm{E}_{1}{ }^{\mathrm{f}}$ and ten heterozygotes with $\mathrm{E}_{1}{ }^{\mathrm{u}} \mathrm{E}_{1} \mathrm{~s}$ were detected in this family. The individual shown as VI-4 in the family tree was a 4 months. old baby at first time examination of 13 years ago. Last year, we were happened to perform a follow up study which confirmed the results with those found previously.

The propositus of the second family, discovered in 1969, was a 3 yr-old girl patient weighing $12.5 \mathrm{~kg}$ with cystinuria (Fig. 1-2) (Iuchi, 1969b). She was admitted. to the Kurashiki Central Hospital for removal of nephro- and ureteroliths. When a dose of $10 \mathrm{mg}$ of SCC was given as a preliminary step in anesthesia for her left ureterolithitomy, an unexpected prolonged apnea lasting $230 \mathrm{~min}$ occurred; her serum specimen was sent to our laboratory, which showed in retrospect that her PsChE activity was completely absent. The second operation for her right pyelolithitomy was performed without using SCC and no prolonged apnea occurred.

Family study revealed seven heterozygotes with $\mathrm{E}_{1} \mathrm{E}_{\mathrm{1}}^{\mathrm{s}}$ and this PsChE anomaly was independent from cystinuria since gene segregation of the two anomalies was clearly observed.

The third case was a 50 yr-old house wife with slight gastritis (Fig. 1-3). The activity of her PsChE was completely absent indicating she was homozygous for the silent gene. Family study demonstrated two other silent gene homozygotes and three heterozygotes. All these family members, except the proband, were apparently healthy.

Since the first discovery of the aberrant PsChE 13 years ago, thirteen families in total have been studied and phenotyped as shown in Fig. 1. It was evident that the clinical symptoms complained of by the patient at the time of admission showed. no relation to the presence of the PsChE anomaly. They seemed to be distributed sporadically all over Japan, and all the families except for No. 13 were the silent gene type. Homozygotes for the $\mathrm{E}_{1}{ }^{\mathrm{a}}$ or $\mathrm{E}_{1}{ }^{\mathrm{f}}$ gene, which are significantly distributed among the Europeans, still remain undiscovered in Japan. The types of PsChE deficiency have been differentiated by Type I ( $O$ type deficiency) and Type II (presence of trace amounts of enzyme, $T$ type) which are defined by Rubinstein (Rubinstein, 1970) and Scott (Scott, 1973). Our families, numbers 2, 3, 4, 5, 8, 9, 11 and 12 are classified as Type $I$ and families $1,6,7$ and 10 as Type II. These classifications of the families were supported by the isozyme staining of $\mathrm{PsChE}$ on polyacrylamide slab gel electrophoresis (pH 8.0) and immunologic assay by Ouchterlony's double diffusion technics. The type I anomaly were truely anenzymic with complete disappearance of $\mathrm{C}_{1}, \mathrm{C}_{2}, \mathrm{C}_{3}$ and $\mathrm{C}_{4}$ components which are usually seen in normal sera, while the Type II anomalies revealed $2-10 \%$ activity, and showed a faintly stained $\mathrm{C}_{4}$ band.

The other type of PsChE anomaly was a patient exhibiting unusually high. 
PsChE activity with evidence of its heredity transmission shown in Fig. 1-13. The proband was a 32 yr-old male patient with paralysed lower extremities because of head injury at age of 3 . The mother was also a carrier without any other abnormalities in her blood chemistry examination and was apparently healthy. The proband's PsChE activity was four times higher than normal. DN and FN were normal. Isozyme study demonstrated an extra band between $\mathrm{C}_{4}$ and $\mathrm{C}_{5}$ band. The biochemical characteristics of this enzyme were similar to the Cynthiana type PsChE anomaly described by Yoshida (Yoshida and Motulsky, 1969).

As for the $\mathrm{C}_{5}$ band, it is electrophoretically seen at the cathodic site of $\mathrm{C}_{4}$ band in some normal persons and the gene responsible for this enzyme is designated as $E_{2}$, which is located at different position from $E_{1}$ gene locus. The carrier with this component reveals $10-30 \%$ higher activity than the non-carrier. The carrier of the $\mathrm{E}_{2}$ locus in Japan was estimated by our survey to be about $5 \%$.

The instances of PsChE anomalies reported during the past 14 years in Japan are summarized in Table 1. It is conjectured that the frequency of the PsChE anomaly in Japan is quite rare compared with those of European countries possibly because of a paucity of publications. Of these reports, individuals detected by SCC hypersensitivity included only two patients of which was our second family. The remaining families have been detected by noticing unusually low activity PsChE which is measured as one of the routine hepatic function tests in the clinical laboratory. Therefore, it might be true the deficiency type of PsChE are more easily detected than the other $E_{1}{ }^{a}$ or $E_{1}{ }^{f}$ type since the latter two types necessitate the additional determinations of DN and FN. Accordingly, the frequency of these gene in the order of $\mathrm{E}_{1} \mathrm{~s}$ (Type I) $>\mathrm{E}_{1} \mathrm{~s}$ (Type II) $>\mathrm{E}_{1}^{\mathrm{a}} \doteqdot \mathrm{E}_{1}^{\mathrm{f}}$ in Table 1 may be partially biased.

\section{Population surveys}

As preliminary experiments, the activity and the inhibition number by six agents

Table 1. Collected PsChE anomalies in Japan.

\begin{tabular}{|c|c|c|c|c|c|c|}
\hline \multicolumn{6}{|c|}{ Phenotype } & \\
\hline \multicolumn{2}{|c|}{$\begin{array}{c}\text { Homozygote } \\
\text { (individual/family) }\end{array}$} & \multicolumn{2}{|c|}{$\begin{array}{l}\text { Double heterozygote } \\
\text { (individual/family) }\end{array}$} & \multicolumn{2}{|c|}{$\begin{array}{c}\text { Heterozygote } \\
\text { (individual/family) }\end{array}$} & \multirow{4}{*}{$\begin{array}{l}\text { From our case } \\
\text { reports }\end{array}$} \\
\hline $\mathrm{E}_{1} \mathrm{SIE}_{1} \mathrm{SI}$ & $10 / 7$ & \multirow{3}{*}{$\mathrm{E}_{1} \mathrm{SIIE}_{1} \mathrm{f}$} & \multirow{3}{*}{$1 / 1$} & $\mathrm{E}_{1} \mathrm{SIE}_{1} \mathrm{u}$ & $13 / 8$ & \\
\hline $\mathrm{E}_{1}$ SIIE $_{1}$ SII & $8 / 5$ & & & $\mathrm{E}_{1} \operatorname{SII}_{\mathrm{E}_{1} \mathrm{u}}$ & $15 / 4$ & \\
\hline EcynEcyn & $1 / 1$ & & & $\operatorname{Ecyn}_{\mathrm{E}_{1}} \mathrm{u}$ & $1 / 1$ & \\
\hline $\mathrm{E}_{1} \mathrm{SIE}_{1} \mathrm{SI}$ & $6 / 5$ & $\mathrm{E}_{1} \mathrm{SIE}_{1} \mathrm{f}$ & $1 / 1$ & & & From the \\
\hline \multirow[t]{2}{*}{$\mathrm{E}_{1}$ SIIE $_{1}$ SII } & 0 & $\mathrm{E}_{1} \mathrm{SIE}_{1}^{\mathrm{a}}$ & $3 / 1$ & & & Reference \\
\hline & & $\mathrm{E}_{1} \operatorname{SIIE}_{1} \mathrm{f}$ & $1 / 1$ & & & in Japan \\
\hline
\end{tabular}

Silent genes of Type $I$ and Type II are expressed as $E_{1}$ SI and $E_{1}$ SII respectively 
were compared between two groups of 60 healthy people (male 30 and female 30) and 530 hospital patients. Results between the two groups indicated different activities but identical inhibition numbers, as expected. No sex differences were observed in the results. Normal values of the determination were then established as follows: Activity, 110-200 unit; DN, 84.04 \pm 3.49 ; FN, 67.12 $\pm 6.10 ; \mathrm{SN}, 71.70 \pm$ 5.04 ; CN, 42.08 \pm 7.58 ; PN, 96.69 \pm 2.58 ; Alcohol number $139 \pm 17.42$. The inhibition numbers were practically the same value as those reported in the original papers.

The results of survey of PsChE totaling 1,945 specimens, demonstrated the existence of two and one individuals heterozygous for the $E_{1}{ }^{f}$ and $E_{1}{ }^{a}$ gene respectively and none homozygous or doubly heterozygous for these gene. This result was practically the same as that of survey which was performed by us 12 years ago in total of 2,050 specimens (Iuchi, 1969a). From these data combined, the frequency of the $E_{1}^{f}$ heterozygote was calculated as $1 / 800$ and that of the $E_{1}$ a heterozygote was $1 / 4,000$. The frequency of silent gene could not be estimated by the screening tests because only the pathological sera were submitted to our laboratory.

A few surveys of PSChE anomaly in Japan have been carried out in the past 14 years. It appears that a total of 7,647 individuals have been screened and ten families with the phenotypes $E_{1}{ }^{u} E_{1}{ }^{a}$ or $E_{1}{ }^{u} E_{1}{ }^{f}$ have been detected in an approximate frequency of 0.0018 . This result is consistent with the previous conjecture of very rare existence of aberrant PsChE genes in Japan.

However, aberrant genes, particularly the $\mathrm{E}_{1}^{\mathrm{s}}$ gene, are certainly distributed with smaller but significant frequencies in the Japanese, in contrast to $3-6 \%$ for the $E_{1}{ }^{a}$ and $E_{1}{ }^{f}$ genes in Caucasian populations and in Middle East Asians, and $20 \%$ of $E_{1} \mathrm{~s}$ in the Eskimos of Western Alaska. The elucidation of these differences awaits future study.

\section{REFERENCES}

Chautard-Freire-Maia, E.A. 1977. Possible assignment of the serum cholinesterase $\left(E_{1}\right)$ and transferrin $\left(\mathrm{T}_{f}\right)$ loci to chromosome 1 in man. Human Hered. 27: 134-142.

Harris, H., and Whittaker, M. 1961. Differential inhibition of human serum cholinesterase with fluoride: Recognition of two new phenotypes. Nature 191: 496-498.

Iuchi, I., Ameno, S., and Shibata, S. 1969a. Survey of atypical pseudocholinesterasemia in Okayama district and a new method for its detection. Bull. Yamaguchi Med. Sch. 16: 35-44.

Iuchi, I., and Shibata, S. 1969b. Another Japanese kindred of pseudocholinesterasemia. Proc. $J_{p n}$. Acad. 45: 824-828.

Kalow, W. 1959. Cholinesterase types. In Ciba Foundation Symposium on Biochemistry of Human Genetics (Wolstenholme et al., ed.), Churchil, London, pp. 39-59.

Kalow, W., and Lindsay, H.A. 1955. A comparison of optical and manometric method for the assay of human serum cholinesterase. Canad. J. Biochem. Physiol. 33: 568-574.

Pantzuck, E.J., and Pantzuck, C.B. 1975. Cholinesterase and anticholinesterases. In Muscle Relaxants (Katz, R., ed.), Am. Elsevier, pp. 143-162.

Rubinstein, H.M. et al. 1970. Silent cholinesterase gene: Variation in the properties of serum enzyme in apparent homozygote. J. Clin. Invest, 49: 479-486. 
Scott, E.M. 1973. Inheritance of two types of deficiency of human serum cholinesterase. Ann. Hum. Genet. (London) $37:$ 139m143.

Shibta, S., Iuchi, I., and Hashimoto, Y. 1967. A consanguineous kindred of serum pseudocholinesterase anomaly found in Japan. Proc. Jpn. Acad. 43: 907-912.

Silver, A. 1974. The biology of cholinesterases. Frontier of Biology, Vol. 36, North-Holland.

Viby-Mogensen, J., and Hanel, H.K. 1978. Prolonged apnea after suxamethonium. Acta Anaesth. Scand. 22: 371-380.

Whittaker, M. 1980. Plasma cholinesterase variants and the anaesthetist. Anaesthesia 35: 174197.

Yoshida, A., and Motulsky, A.G. 1969. A pseudocholinesterase variant (E Cynthiana) associated with elevated plasma enzyme activity. Am. J, Hum. Genet. 24: 486-498. 